\title{
Mechanically Activated Combustion Synthesis of Molybdenum Borosilicides for Ultrahigh- Temperature Structural Applications
}

\author{
Alan A. Esparza and Evgeny Shafirovich* \\ Department of Mechanical Engineering, The University of Texas at El Paso, El Paso, TX 79968 \\ "Corresponding Author Email: eshafirovich2@utep.edu
}

\begin{abstract}
The thermal efficiency of gas-turbine power plants could be dramatically increased by the development of new structural materials based on molybdenum silicides and borosilicides, which can operate at temperatures higher than $1300{ }^{\circ} \mathrm{C}$ with no need for cooling. A major challenge, however, is to simultaneously achieve high oxidation resistance and acceptable mechanical properties at high temperatures. Materials based on $\mathrm{Mo}_{5} \mathrm{SiB}_{2}$ (called $\mathrm{T}_{2}$ ) phase are promising materials that offer favorable combinations of high temperature mechanical properties and oxidation resistance. In the present paper, $\mathrm{T}_{2}$ phase based materials have been obtained using mechanically activated self-propagating high-temperature synthesis (MASHS). Upon ignition, $\mathrm{Mo} / \mathrm{Si} / \mathrm{B} / \mathrm{Ti}$ mixtures exhibited a self-sustained propagation of a spinning combustion wave, but the products were porous, contained undesired secondary phases, and had low oxidation resistance. The "chemical oven" technique has been successfully employed to fabricate denser and stronger $\mathrm{Mo}_{5} \mathrm{SiB}_{2}-\mathrm{TiC}, \mathrm{Mo}_{5} \mathrm{SiB}_{2}-\mathrm{TiB}_{2}$, and $\mathrm{Mo}-\mathrm{Mo}_{5} \mathrm{SiB}_{2}-\mathrm{Mo}_{3} \mathrm{Si}$ materials. Among them, $\mathrm{Mo}_{5} \mathrm{SiB}_{2}-\mathrm{TiB}_{2}$ material exhibits the best oxidation resistance at temperatures up to $1500{ }^{\circ} \mathrm{C}$.
\end{abstract}

Keywords: Intermetallics, Combustion synthesis, SHS, Mechanical activation, Oxidation

(C) 2016. This manuscript version is made available under the Elsevier user license http://www.elsevier.com/open-access/userlicense/1.0/ 


\section{Introduction}

The thermal efficiency of gas-turbine power plants could be increased by the development of new structural materials based on molybdenum silicides and borosilicides, which can operate at temperatures higher than $1300{ }^{\circ} \mathrm{C}$ with no need for cooling [1-4]. Molybdenum disilicide $\left(\mathrm{MoSi}_{2}\right)$ has a high melting point $\left(2030^{\circ} \mathrm{C}\right)$ and excellent high-temperature oxidation resistance, but a single $\mathrm{MoSi}_{2}$ phase has low fracture toughness at room temperature and low strength at elevated temperatures [5]. The mechanical properties of Mo-richer silicides such as $\mathrm{Mo}_{5} \mathrm{Si}_{3}$ (called $\mathrm{T}_{1}$ ) phase and $\mathrm{Mo}_{3} \mathrm{Si}$ are better, but they have lower oxidation resistance $[4,5]$.

A promising approach focuses on adding boron to Mo-rich silicides [6]. The addition of boron improves oxidation resistance because of the formation of a borosilicate surface layer [1, 6]. This has promoted interest in fabricating $\mathrm{Mo}_{5} \mathrm{SiB}_{2}$ (called $\mathrm{T}_{2}$ ) phase.

Boron addition, however, makes silicides brittle. One way to toughen these mixtures is to add molybdenum phase. Three-phase $\alpha-\mathrm{Mo}-\mathrm{Mo}_{5} \mathrm{SiB}_{2}-\mathrm{Mo}_{3} \mathrm{Si}$ (e.g., $\mathrm{Mo}-12 \mathrm{Si}-8.5 \mathrm{~B}$ ) alloys are considered as promising materials that combine good oxidation resistance and acceptable mechanical properties [7-9].

A novel method for improving the mechanical properties of $\mathrm{Mo}_{5} \mathrm{SiB}_{2}$ materials involves the addition of titanium carbide (TiC), which has a melting point of $3160 \mathrm{~K}$ and a modulus of elasticity of $379 \mathrm{GPa}$ at $1000{ }^{\circ} \mathrm{C}$ [10]. Recently, it has been shown that the addition of $\mathrm{TiC}$ improves the compression strength of $\mathrm{Mo}-\mathrm{Si}-\mathrm{B}$ materials at high temperatures $[11,12]$.

One more potential additive to $\mathrm{T}_{2}$ phase is titanium diboride $\left(\mathrm{TiB}_{2}\right)$. The melting point of $\mathrm{TiB}_{2}$ is $3230{ }^{\circ} \mathrm{C}$ and its elastic modulus is $534 \mathrm{GPa}$ at $1000{ }^{\circ} \mathrm{C}$ [13], i.e. these properties of $\mathrm{TiB}_{2}$ are even better than those of TiC. However, to the best of our knowledge, the phase diagram for $\mathrm{TiB}_{2}$ and Mo-Si-B phases is not available and no attempt has been made to fabricate $\mathrm{Mo}_{5} \mathrm{SiB}_{2}-$ $\mathrm{TiB}_{2}$ materials.

The synthesis of Mo-Si-B multi-phase alloys is usually difficult because of their extremely high melting temperatures. Mechanical alloying has been considered as a promising method for manufacturing these materials $[9,14,15]$. This method, however, requires relatively long milling times (typically 10-100 h), leading to large energy consumption and contamination of the product by grinding media [9].

It would be attractive to use self-propagating high-temperature synthesis (SHS) for the fabrication of $\mathrm{T}_{2}$ phase based alloys. A major problem, however, is low exothermicities of mixtures for producing these materials. One promising method for enabling the SHS process in low-exothermic mixtures is mechanical activation of the powders, i.e., a short-duration, highenergy ball milling step before the combustion process $[16,17]$. The entire procedure is usually called mechanical activation-assisted (or mechanically activated) self-propagating hightemperature synthesis (MASHS). The high-energy milling enables intermixing of reactive components on a very small scale. The fracture-welding process during milling increases the contact surface area and destroys the oxide layer on the particle surface. As a result, mechanical activation improves the reaction kinetics, leading to an easier ignition and stable combustion. Also, the short milling time eliminates the problem of product contamination by milling media, typical for mechanical alloying. In general, the MASHS technique combines the advantages of mechanical alloying and SHS, also allowing for the formation of materials that cannot be obtained by either of these techniques if used alone.

Sometimes, however, the use of mechanical activation is insufficient for ignition. In such cases, the exothermicity can be increased by changing the mixture ratio. For example, in the prior research [18], mixtures with $\mathrm{Mo} / \mathrm{Si} / \mathrm{B}$ mole ratio of 5:1:2 (which corresponds to $\mathrm{T}_{2}$ phase) 
did not burn, while changing the composition toward two products, viz. $\mathrm{T}_{2}$ phase and MoB, resulted in a self-sustained combustion. Note that in these experiments, a spinning combustion wave was observed, with the motion of hot spots along a helix on the pellet surface. This regime, called spin combustion, occurs in some low-exothermic mixtures when the released heat is not sufficient for maintaining a planar combustion front [19-22].

Based on results [18], one may expect that promising $\mathrm{Mo}_{5} \mathrm{SiB}_{2} / \mathrm{TiC}$ and $\mathrm{Mo}_{5} \mathrm{SiB}_{2} / \mathrm{TiB}_{2}$ materials can be fabricated by MASHS of Mo/Si/B mixtures with added Ti/C or Ti/B mixtures because the reactions of $\mathrm{Ti}$ with $\mathrm{C}$ and $\mathrm{B}$ are highly exothermic (the formation enthalpies of $\mathrm{TiC}$ and $\mathrm{TiB}_{2}$ are $-184.10 \mathrm{~kJ} / \mathrm{mol}$ and $-279.49 \mathrm{~kJ} / \mathrm{mol}$, respectively [23], and the adiabatic flame temperatures of stoichiometric $\mathrm{Ti} / \mathrm{C}$ and $\mathrm{Ti} / 2 \mathrm{~B}$ mixtures, calculated at 1 atm pressure with THERMO software [24], are $3290 \mathrm{~K}$ and $3193 \mathrm{~K}$, respectively).

Another method for burning low-exothermic mixtures is the so-called "chemical oven," where the sample is surrounded by a layer of a highly exothermic mixture such as Ti/C or Ti/B. Combustion of this layer releases enough heat for enabling ignition and combustion of the core material. Recently, this method has been successfully employed for the fabrication of $T_{2}$ phase [25].

The objective of the present work was to investigate the feasibility of using MASHS for the fabrication of promising materials based on $\mathrm{Mo}_{5} \mathrm{SiB}_{2}$ phase such as $\alpha-\mathrm{Mo} / \mathrm{Mo} \mathrm{SiB}_{2} / \mathrm{Mo}_{3} \mathrm{Si}$, $\mathrm{Mo}_{5} \mathrm{SiB}_{2} / \mathrm{TiC}$, and $\mathrm{Mo}_{5} \mathrm{SiB}_{2} / \mathrm{TiB}_{2}$ materials. First, the attempts were made to synthesize the materials with $\mathrm{TiC}$ and $\mathrm{TiB}_{2}$ phases using $\mathrm{SHS}$ in $\mathrm{Mo} / \mathrm{Si} / \mathrm{B}$ mixtures with added $\mathrm{Ti} / \mathrm{C}$ and $\mathrm{Ti} / \mathrm{B}$. Next, the chemical oven technique was used to fabricate these materials and $\alpha-\mathrm{Mo}_{-}-\mathrm{Mo}_{5} \mathrm{SiB}_{2}-$ $\mathrm{Mo}_{3} \mathrm{Si}$ alloys as well. Characterization of the obtained materials included X-ray diffraction analysis, determination of mechanical properties, and oxidation studies involving thermoanalytical methods.

\section{Experimental}

Molybdenum (99.95\% pure, Climax Molybdenum), silicon (crystalline, 99.5\% pure, Alfa Aesar), boron (amorphous, 94-96\% pure, Alfa Aesar), graphite (crystalline, 99\% pure, Alfa Aesar), and titanium (99.5\% pure, Alfa Aesar) powders were used in this study.

The powders were mixed in a three-dimensional inversion kinematics tumbler mixer (Inversina 2L, from Bioengineering, Inc.) for $1 \mathrm{~h}$ and then milled in a planetary ball mill (Fritsch Pulverisette 7 premium line). Zirconia-coated $80-\mathrm{mL}$ bowls were used. The grinding media were 1.5-mm zirconia balls. The mixture to ball mass ratio was equal to 1:6. The milling process was conducted in an argon environment. It included 4 milling-cooling cycles (10 min milling at the maximum rotation speed of $1100 \mathrm{rpm}$ and $75 \mathrm{~min}$ cooling). As reported previously [18], after this milling regime, the particle size of $\mathrm{Mo} / \mathrm{Si}$ or $\mathrm{Mo} / \mathrm{Si} / \mathrm{B}$ mixtures decreases from about $10 \mu \mathrm{m}$ to the submicron range $(200-500 \mathrm{~nm})$, while X-ray diffraction analysis detects only initial reactants with no products.

To fabricate $\mathrm{Mo}_{5} \mathrm{SiB}_{2}-\mathrm{TiC}$ materials by conventional SHS (with no external heat), four compositions were tested. Different amounts (10 wt $\%, 20 \mathrm{wt} \%, 30 \mathrm{wt} \%$, and 40\%) of stoichiometric $\mathrm{Ti} / \mathrm{C}$ (1:1 mole ratio) mixture were added to the main $\mathrm{Mo} / \mathrm{Si} / \mathrm{B}$ (5:1:2 mole ratio) mixture. To fabricate $\mathrm{Mo}_{5} \mathrm{SiB}_{2}-\mathrm{TiB}_{2}$ materials by the same technique, five compositions were tested. Different amounts (10 wt \%, $15 \mathrm{wt} \%, 20 \mathrm{wt} \%, 30 \mathrm{wt} \%$, and $40 \mathrm{wt} \%)$ of stoichiometric Ti$\mathrm{B}$ (1:2 mole ratio) mixture were added to $\mathrm{Mo} / \mathrm{Si} / \mathrm{B}$ (5:1:2 mole ratio) mixture. The resulting mixtures were compressed into cylindrical pellets (diameter $13 \mathrm{~mm}$ ) in a uniaxial hydraulic press 
(Carver) with a compressive force of $35-40 \mathrm{kN}$. Before compacting, a layer of Ti/B (1:2 mole ratio) booster mixture was placed on the top of the pellet. The height of the main mixture was $12-15 \mathrm{~mm}$ and the height of the booster layer was about $3 \mathrm{~mm}$. The relative densities of the tested mixtures were in the range of 57-66\%.

In the chemical oven technique, composite pellets were prepared that included a core made of the main mixture and a shell made of the Ti/B booster mixture. The core compositions for fabricating $\mathrm{Mo}_{5} \mathrm{SiB}_{2}-\mathrm{TiC}$ and $\mathrm{Mo}_{5} \mathrm{SiB}_{2}-\mathrm{TiB}_{2}$ materials consisted of $85 \mathrm{wt} \% \mathrm{Mo} / \mathrm{Si} / \mathrm{B}$ (5:1:2 mole ratio) mixture and $15 \mathrm{wt} \% \mathrm{Ti} / \mathrm{B}(1: 2 \mathrm{~mole}$ ratio) or $\mathrm{Ti} / \mathrm{C}(1: 1$ mole ratio) mixture. The core compositions for fabricating $\alpha-\mathrm{Mo}-\mathrm{Mo}_{5} \mathrm{SiB}_{2}-\mathrm{Mo}_{3} \mathrm{Si}$ materials consisted of $\mathrm{Mo}, \mathrm{Si}$, and $\mathrm{B}$ mixed according to the composition of Mo-12Si-8.5B alloy. To make the composite pellet, first, the core mixture was compacted into a pellet (diameter: $13 \mathrm{~mm}$, height: $12.8-14.0 \mathrm{~mm}$ ) using a force of $35-40 \mathrm{kN}$. Then this pellet was submerged into Ti/B mixture inside a $25-\mathrm{mm}$ die and pressed again. The resulting composite pellet had a height of 23-26 mm. This pellet was wrapped by 3mm-thick thermal paper (Fiberfrax). Figure 1 shows sketches of pellets prepared for conventional SHS and chemical oven experiments.

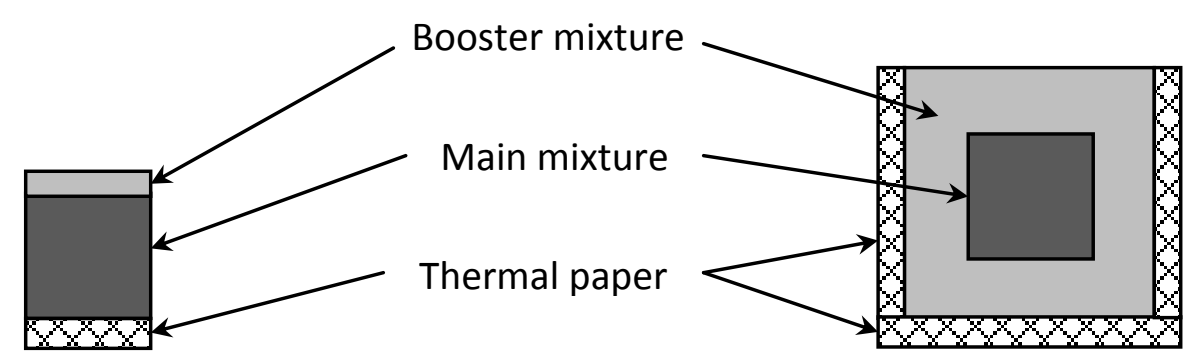

Fig. 1. Sketches of pellets prepared for conventional SHS (left) and chemical oven experiments (right).

The combustion experiments were conducted in a 30-L stainless steel reaction chamber. A schematic diagram of the setup is shown elsewhere [26]. The pellet was installed vertically on a ceramic fiber insulator (Fiberfrax). The chamber was evacuated and filled with ultrahigh purity argon at $1 \mathrm{~atm}$. The pellet was heated by a tungsten wire connected to a DC power supply. During conventional SHS, propagation of the combustion front over the pellet was observed, while in the chemical oven experiments, it was possible to only see bright light emitted by the burning shell. In both types of experiments, the power supply was shut off upon the ignition of the booster mixture.

WRe5\%/WRe26\% thermocouples (type C, wire diameter: $76 \mu \mathrm{m}$, Omega Engineering) were used to measure the temperature in the middle of the sample during the combustion process. The thermocouples, located in two-channel ceramic insulators, were inserted into pellets through drilled channels. The thermocouples were connected to a USB-based data acquisition system (National Instruments USB-9211).

A high-speed video camera (Vision Research Phantom v1210), equipped with a lens for macro shooting (Nikon AF Micro NIKKOR 60mm f/2.8D), was used for observations of the combustion process through a glass window. In the present research, the resolution was $1024 \times 768$ and the frame rate was $500 \mathrm{fps}$.

The as-milled powders and combustion products were analyzed using X-ray diffraction (Bruker D8 Discover XRD). Oxidation resistance of the obtained materials was studied using a thermogravimetric analyzer (Netzsch TGA 209 F1 Iris) and a differential scanning calorimeter 
(Netzsch DSC 404 F1 Pegasus). The TGA and DSC instruments were calibrated following manufacturer recommendations. The compressive strength of the obtained materials was measured using a fatigue testing machine (INSTRON 8801) in accordance with ASTM standard C773. The elastic modulus and hardness were determined using a nanomechanical test instrument (Hysitron TI 750H Ubi).

\section{Results and Discussion}

\subsection{Synthesis of $\mathrm{Mo}_{5} \mathrm{SiB}_{2}-\mathrm{TiC}, \mathrm{Mo}_{5} \mathrm{SiB}_{2}-\mathrm{TiB}_{2}$, and $\alpha-\mathrm{Mo}-\mathrm{Mo}_{5} \mathrm{SiB}_{2}-\mathrm{Mo}_{3} \mathrm{Si}$ materials}

Attempts to ignite $\mathrm{Mo} / \mathrm{Si} / \mathrm{B} / \mathrm{Ti} / \mathrm{C}$ mixtures, designed to obtain $\mathrm{Mo}_{5} \mathrm{SiB}_{2}-\mathrm{TiC}$, using a booster pellet at the top were unsuccessful. In contrast, $\mathrm{Mo} / \mathrm{Si} / \mathrm{B} / \mathrm{Ti}$ mixtures (for $\mathrm{Mo}_{5} \mathrm{SiB}_{2}-\mathrm{TiB}_{2}$ materials) ignited successfully. In the mixture designed for $10 \mathrm{wt} \% \mathrm{TiB}_{2}$, however, the combustion front stopped at the middle of the pellet, while the mixtures with higher concentration of Ti/B additive burned entirely. Figure 2 and Supplementary Video 1 show the combustion propagation over the mixture designed for $15 \mathrm{wt} \% \mathrm{TiB}_{2}$. It is seen from the top series of images in Fig. 2 that the combustion front propagates downward with an approximately constant axial velocity (about $4 \mathrm{~mm} / \mathrm{s}$ ). The bottom series of images in Fig. 1 reveals a spinning structure of the combustion wave. Specifically, a counter-propagating motion is seen in the images with time labels $0.08 \mathrm{~s}$ and $0.1 \mathrm{~s}$. This behavior of combustion wave propagation has been reported for the mixtures of JSC-1A lunar regolith simulant with magnesium [22] and obtained in numerical modeling of spin combustion [20,21].

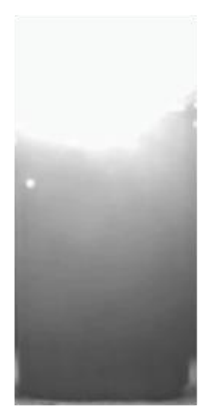

0

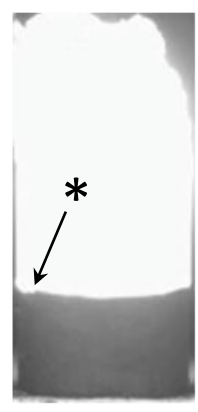

0

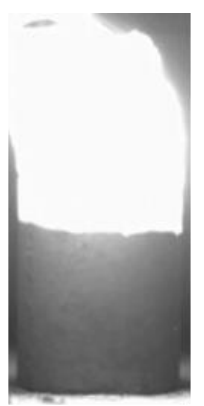

$0.7 \mathrm{~s}$

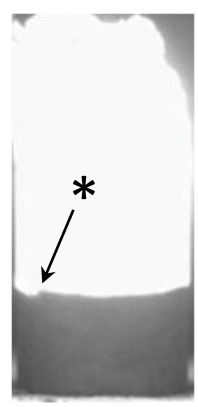

$0.02 s$

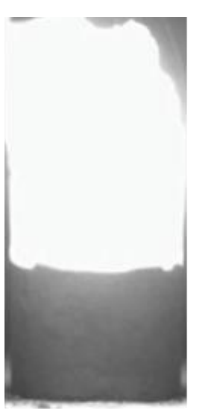

1.4

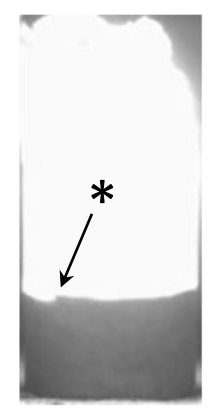

$0.04 \mathrm{~s}$

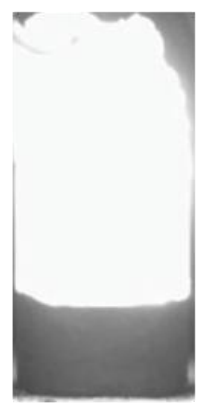

$2.1 \mathrm{~s}$

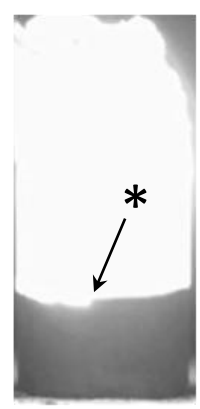

$0.06 \mathrm{~s}$

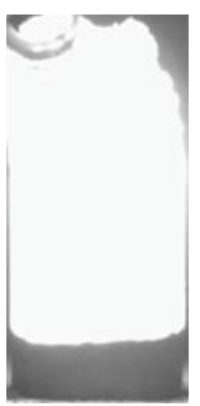

$2.8 \mathrm{~s}$

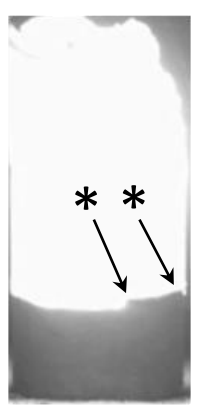

$0.08 \mathrm{~s}$

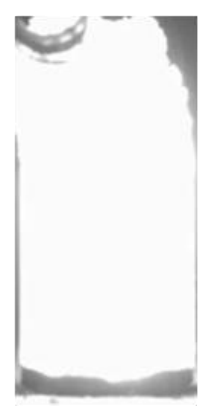

$3.5 \mathrm{~s}$

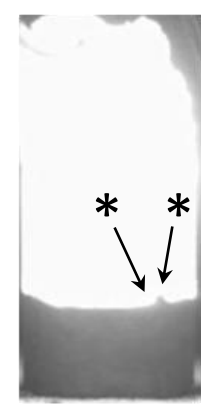

$0.1 \mathrm{~s}$

Fig 2. Combustion of Mo-Si-B-Ti mixture designed for $85 \% \mathrm{Mo}_{5} \mathrm{SiB}_{2}$ and $15 \% \mathrm{TiB}_{2}$. The sample diameter was $13 \mathrm{~mm}$. The top series of images shows the entire process, while the bottom one shows a fragment with shorter intervals between the images. In each series, time zero was selected arbitrarily. The first image in the top series shows combustion of the booster Ti/B layer. Asterisks show the leading edges of the spinning combustion wave. 
As noted in the Introduction, spin combustion occurs in low-exothermic mixtures, i.e. when the combustion temperature is low. Indeed, thermocouple measurements for this mixture have shown that the maximum temperature in the middle of the pellet was only about $1140{ }^{\circ} \mathrm{C}$. Since the maximum temperature did not reach the melting point of $\mathrm{Si}, 1414{ }^{\circ} \mathrm{C}$ (the melting points of Mo and $\mathrm{B}$ are much higher), the reaction mechanism during the observed spin combustion was based on solid-phase diffusion, with no liquid involved.

Figure 3 shows the XRD pattern of products formed after combustion of the mixture designed for $20 \mathrm{wt} \% \mathrm{TiB}_{2}$. It is seen that along with the desired $\mathrm{Mo}_{5} \mathrm{SiB}_{2}$ and $\mathrm{TiB}_{2}$ phases, there are also significant peaks of $\mathrm{Mo}, \mathrm{MoB}$, and $\mathrm{Mo}_{5} \mathrm{Si}_{3}$.

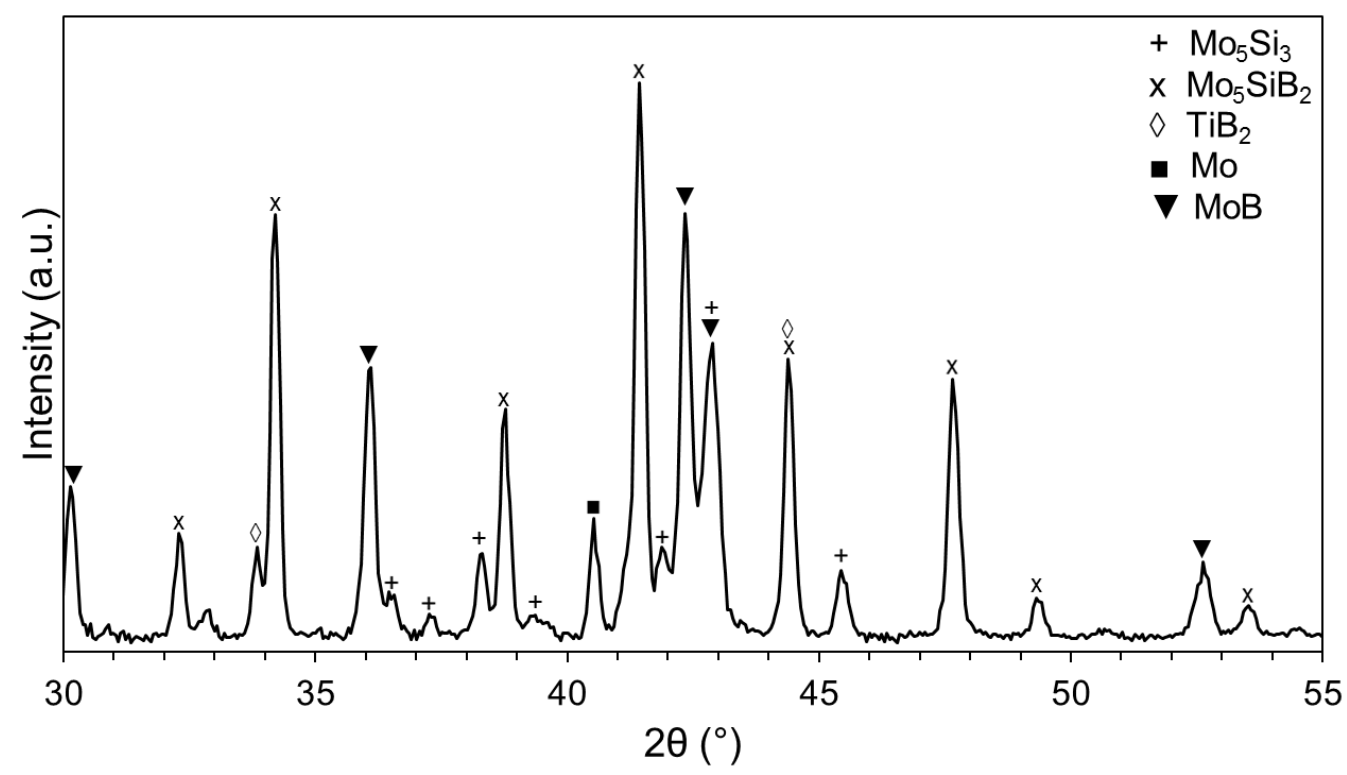

Fig. 3. XRD patterns of products obtained by combustion (conventional SHS) of Mo/Si/B/Ti mixture designed for $80 \% \mathrm{Mo}_{5} \mathrm{SiB}_{2}$ and $20 \% \mathrm{TiB}_{2}$.

With increasing the concentration of $\mathrm{Ti} / \mathrm{B}$ additive, the peak of Mo decreases, but the intensities of MoB peaks increase. For example, Figure 4 shows that in the products formed after combustion of the mixture designed for $40 \mathrm{wt} \% \mathrm{TiB}_{2}$, there is no Mo peak, but MoB becomes the dominant phase. 


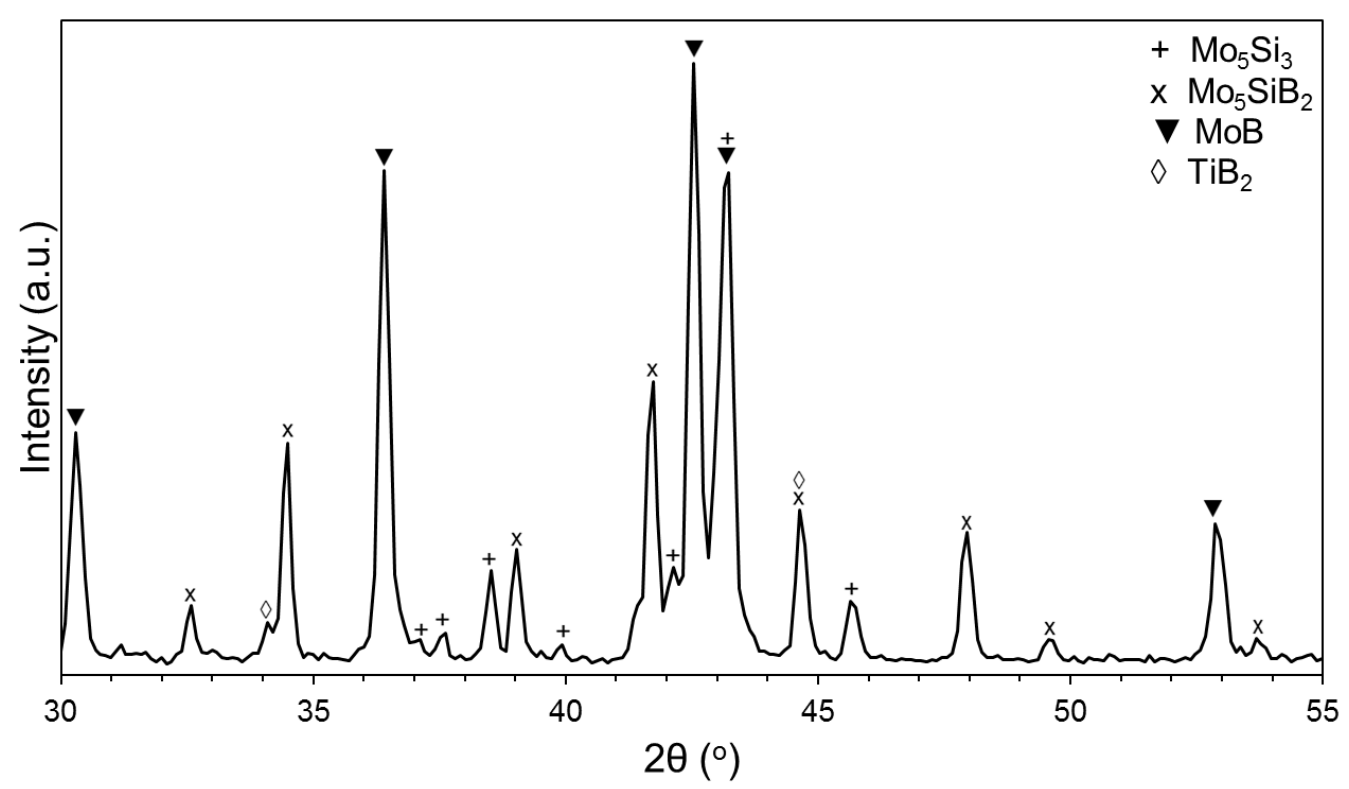

Fig. 4. XRD patterns of products obtained by combustion (conventional SHS) of Mo/Si/B/Ti mixture designed for $60 \% \mathrm{Mo}_{5} \mathrm{SiB}_{2}$ and $40 \% \mathrm{TiB}_{2}$.

These results lead to the conclusion that it is impossible to obtain desired two-phase $\mathrm{Mo}_{5} \mathrm{SiB}_{2}-\mathrm{TiC}$ and $\mathrm{Mo}_{5} \mathrm{SiB}_{2}-\mathrm{TiB}_{2}$ materials by a conventional SHS with ignition at the top of the pellet. For this reason, it was decided to focus on the use of the chemical oven technique. This has enabled successful ignition and combustion of $\mathrm{Mo} / \mathrm{Si} / \mathrm{B} / \mathrm{Ti} / \mathrm{C}$ mixtures. Figure 5 shows the XRD pattern of the products obtained by combustion of $\mathrm{Mo} / \mathrm{Si} / \mathrm{B} / \mathrm{Ti} / \mathrm{C}$ mixture designed for 15 $\mathrm{wt} \% \mathrm{TiC}$. It is seen that $\mathrm{Mo}_{5} \mathrm{SiB}_{2}$ phase dominates, while MoB peaks are relatively small and there are no peaks of $\mathrm{Mo}$ and $\mathrm{Mo}_{5} \mathrm{Si}_{3}$.

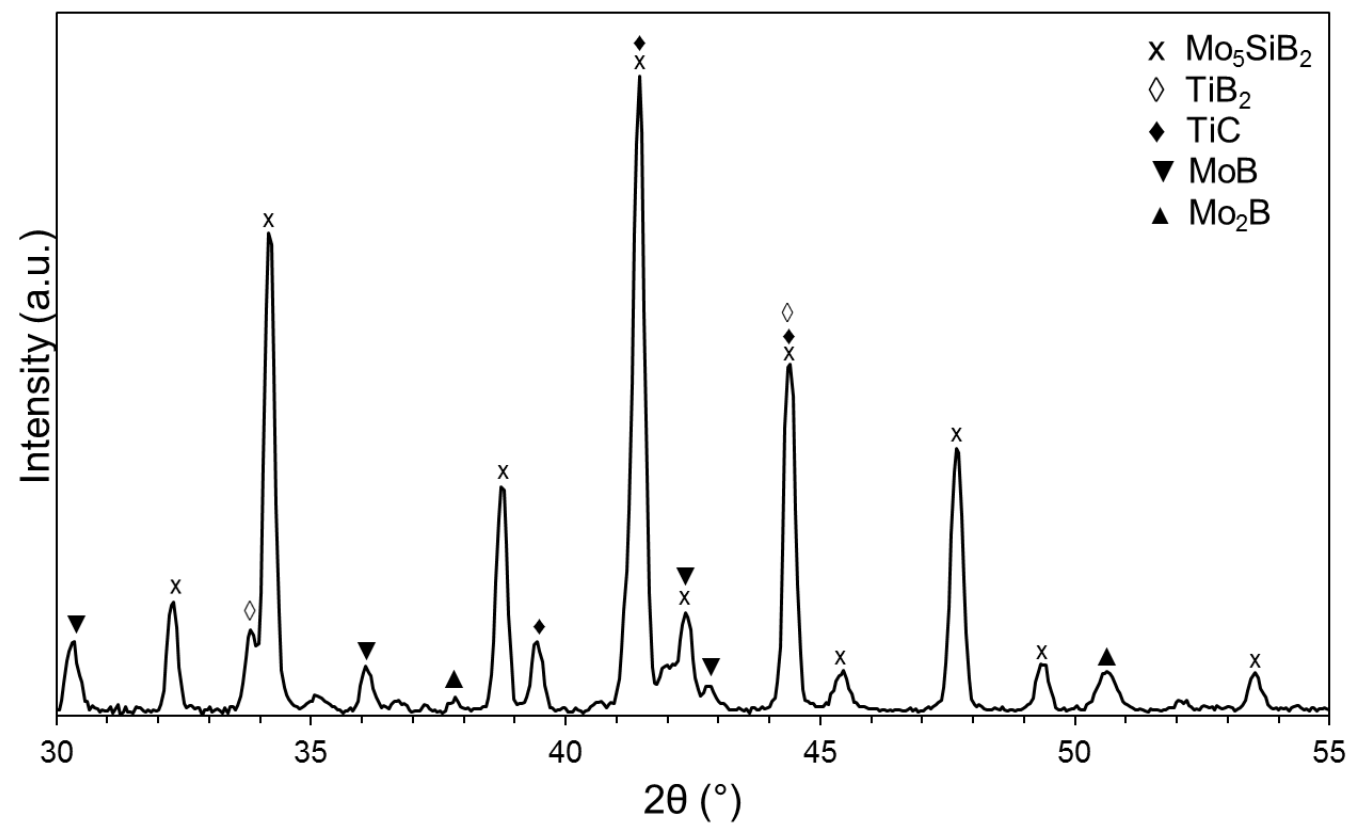

Fig. 5. XRD pattern of products obtained by combustion (chemical oven) of $\mathrm{Mo} / \mathrm{Si} / \mathrm{B} / \mathrm{Ti} / \mathrm{C}$ mixture designed for $85 \% \mathrm{Mo}_{5} \mathrm{SiB}_{2}$ and $15 \% \mathrm{TiC}$. 
The use of the chemical oven technique has also led to a better quality of products obtained by combustion of $\mathrm{Mo} / \mathrm{Si} / \mathrm{B} / \mathrm{Ti}$ mixtures designed for the fabrication of $\mathrm{Mo}_{5} \mathrm{SiB}_{2}-\mathrm{TiB}_{2}$ materials. Figure 6 shows the XRD pattern of the products obtained by combustion of $\mathrm{Mo} / \mathrm{Si} / \mathrm{B} / \mathrm{Ti}$ mixture designed for $15 \mathrm{wt} \% \mathrm{TiB}_{2}$. It is seen that $\mathrm{MoB}$ peaks are relatively small and there are no peaks of $\mathrm{Mo}$ and $\mathrm{Mo}_{5} \mathrm{Si}_{3}$.

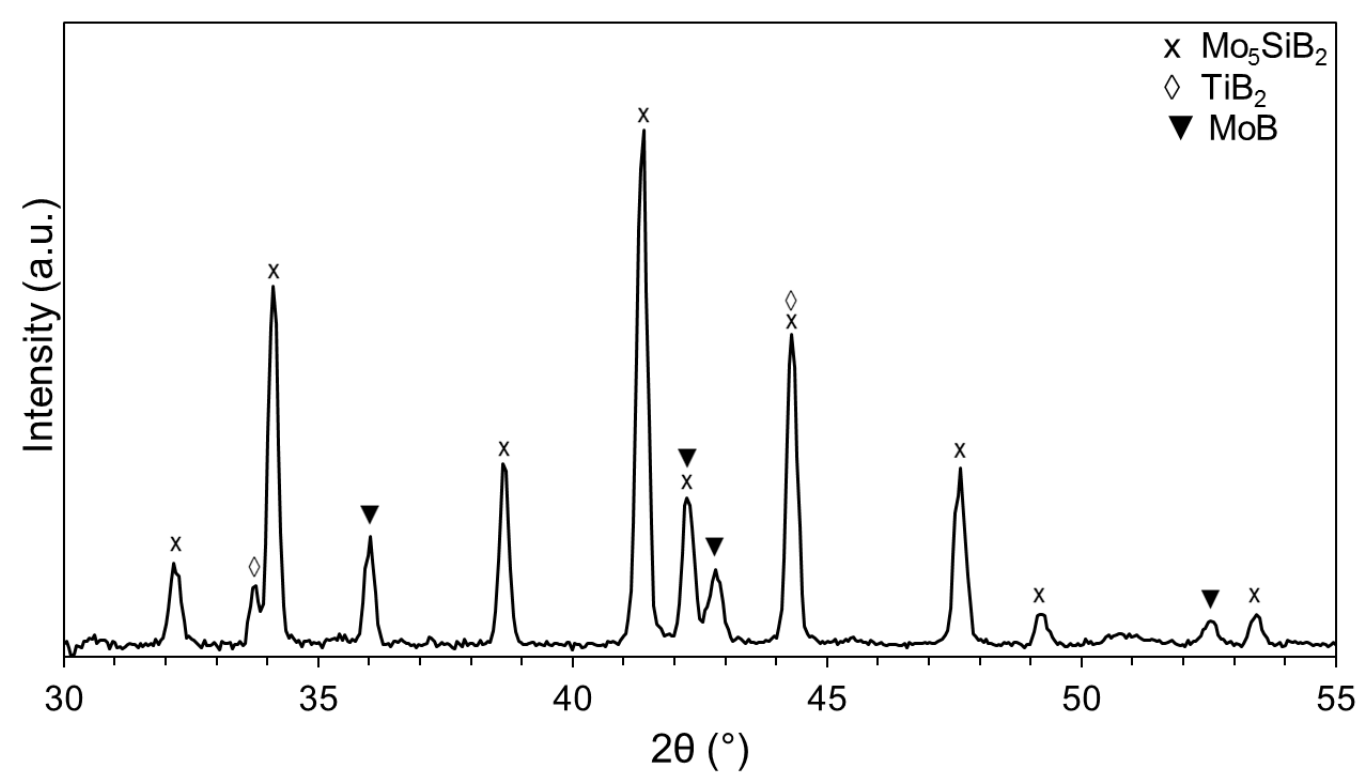

Fig. 6. XRD pattern of products obtained by combustion (chemical oven) of Mo/Si/B/Ti mixture designed for $85 \% \mathrm{Mo}_{5} \mathrm{SiB}_{2}$ and $15 \% \mathrm{TiB}_{2}$.

The lower concentrations of secondary phases in the products obtained by the chemical oven technique are likely associated with the higher temperatures during combustion. Figure 7 shows a time variation of the electromotive force (emf), generated by a C-type thermocouple installed in the center of the pellet of $\mathrm{Mo} / \mathrm{Si} / \mathrm{B} / \mathrm{Ti}$ mixture designed for $85 \% \mathrm{Mo}_{5} \mathrm{SiB}_{2}$ and $15 \% \mathrm{TiB}_{2}$. Since the C-type thermocouple has a highly non-linear temperature characteristic, the curve shows the measured emf, while the dashed gridlines show the emf values calculated for several temperatures using an empirical polynomial formula [27]. It is seen that after the combustion front meets the thermocouple junction (the ignition stage), the temperature fluctuates around $2400{ }^{\circ} \mathrm{C}$ for about $2 \mathrm{~s}$ (the combustion stage) and then gradually decreases (the cooling stage). Since the melting points of $\mathrm{Mo}, \mathrm{Si}, \mathrm{B}$, and $\mathrm{Ti}$ are $2623{ }^{\circ} \mathrm{C}, 1414{ }^{\circ} \mathrm{C}, 2076{ }^{\circ} \mathrm{C}$, and $1668{ }^{\circ} \mathrm{C}$, respectively, it can be concluded that three of the four reactants (viz. $\mathrm{Si}, \mathrm{B}$, and $\mathrm{Ti}$ ) are liquid in the combustion front, which results in a better conversion to thermodynamically expected products than in the case of conventional SHS where temperatures were below the melting point of Si. During the cooling stage, the temperature drops to $1500{ }^{\circ} \mathrm{C}$ for $10 \mathrm{~s}$, to $1000{ }^{\circ} \mathrm{C}$ for $25 \mathrm{~s}$, and to $500{ }^{\circ} \mathrm{C}$ for $80 \mathrm{~s}$. 


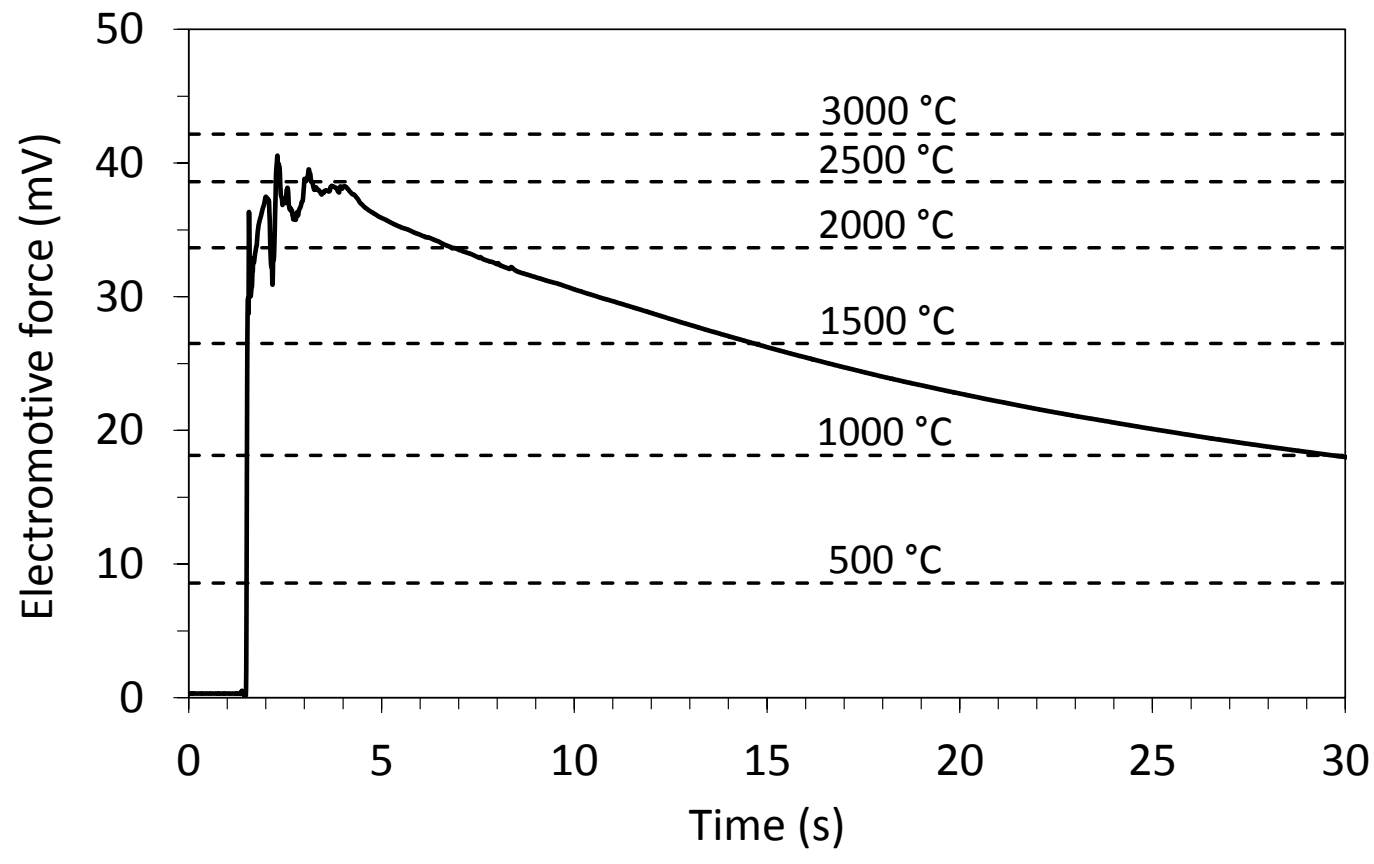

Fig. 7. Time variation of the electromotive force (relative to $0{ }^{\circ} \mathrm{C}$ ) generated by a C-type thermocouple during combustion (chemical oven) of $\mathrm{Mo} / \mathrm{Si} / \mathrm{B} / \mathrm{Ti}$ mixture designed for $85 \% \mathrm{Mo}_{5} \mathrm{SiB}_{2}$ and $15 \% \mathrm{TiB}_{2}$. Time zero was selected arbitrarily.

For all mixtures, conventional SHS process led to the formation of a porous product with cracks. In contrast, the experiments conducted with the chemical oven technique have produced denser materials, with no cracks except for the ends of the pellet. For example, the density of the $\mathrm{TiB}_{2}$-containing material obtained by conventional SHS was $4.0 \mathrm{~g} / \mathrm{cm}^{3}$, while the density of the $\mathrm{TiB}_{2}$-containing material obtained by the chemical oven was $6.7 \mathrm{~g} / \mathrm{cm} .^{3}$ For reference, the theoretical density of $\mathrm{Mo}_{5} \mathrm{SiB}_{2}-\mathrm{TiB}_{2}\left(15 \mathrm{wt} \% \mathrm{TiB}_{2}\right)$ is $8.2 \mathrm{~g} / \mathrm{cm}^{3}$. Although the obtained materials contain secondary phases (see Figs. 4 and 6) and their exact theoretical densities remain unknown, it is clear that the chemical oven technique produced denser materials. For illustration, Figure 8 shows products obtained after combustion of the same mixture in a conventional SHS mode and using the chemical oven technique. The top part of the left pellet is the product of the booster layer combustion (i.e. $\mathrm{TiB}_{2}$ ), while the right pellet is shown after removing the shell of booster mixture products. 


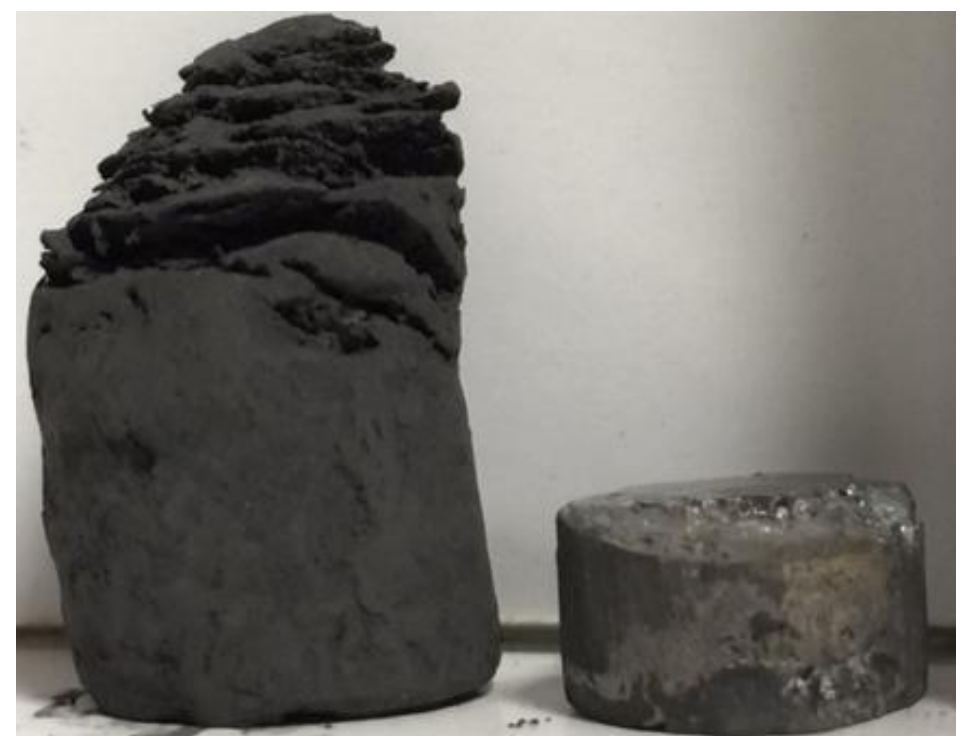

Fig. 8. Combustion products of $\mathrm{Mo} / \mathrm{Si} / \mathrm{B} / \mathrm{Ti}$ mixture designed for $85 \% \mathrm{Mo}_{5} \mathrm{SiB}_{2}$ and $15 \% \mathrm{TiB}_{2}$. The left pellet was obtained by conventional SHS, while the right product was obtained by the chemical oven technique.

The elastic modulus and hardness at room temperature were determined for $\mathrm{Mo}_{5} \mathrm{SiB}_{2}-\mathrm{TiC}$ and $\mathrm{Mo}_{5} \mathrm{SiB}_{2}-\mathrm{TiB}_{2}$ materials obtained by the chemical oven technique. These characteristics are $109 \mathrm{GPa}$ and $1.24 \mathrm{GPa}$, respectively, for $\mathrm{Mo}_{5} \mathrm{SiB}_{2}-\mathrm{TiC}$ material. The obtained $\mathrm{Mo}_{5} \mathrm{SiB}_{2} / \mathrm{TiB}_{2}$ material has better elastic modulus and hardness: $135 \mathrm{GPa}$ and $2.40 \mathrm{GPa}$, respectively. Yet, for both materials these properties are worse than for Mo-Si-B materials reported in the literature [28-30]. This is apparently associated with the insufficient density and significant porosity of the combustion synthesis products. Although the materials obtained by the chemical oven technique are much denser than the products of conventional SHS, much has to be done to achieve the desired relative density of about $100 \%$. For the synthesis of dense, low-porous materials, several SHS modifications have been proposed such as SHS sintering, SHS with explosive consolidation, dynamic compaction or impact forging, hot pressing, and quasi-isostatic pressing [26, 31-37]. For example, relatively dense $\mathrm{Mo}-\mathrm{Si}$ and $\mathrm{Mo}-\mathrm{Si}-\mathrm{B}$ materials have been obtained using SHS followed by quasi-isostatic pressing of still hot combustion products [18, 25].

The chemical oven technique has also enabled combustion synthesis of $\alpha-\mathrm{Mo}-\mathrm{Mo}_{5} \mathrm{SiB}_{2}-$ $\mathrm{Mo}_{3} \mathrm{Si}$ materials. Figure 9 shows a typical XRD pattern of the material obtained from $\mathrm{Mo} / 12 \mathrm{Si} / 8.5 \mathrm{~B}$ mixture. The peaks correspond to the desired $\alpha-\mathrm{Mo}, \mathrm{Mo}_{5} \mathrm{SiB}_{2}$, and $\mathrm{Mo}_{3} \mathrm{Si}$ phases, with no other phases detected. Considering the highest peak for each phase, $\mathrm{Mo} / \mathrm{Mo} 3 \mathrm{Si} / \mathrm{Mo}_{5} \mathrm{SiB}_{2}$ intensity ratio is $3.7: 1.3: 1$. Since the highest peaks of the three phases are close to each other and partly overlap, the intensity ratio was estimated based on the peak heights only. Although accurate quantitative analysis of XRD results was not conducted, it is seen that Mo dominates in the XRD pattern and the highest peak of $\mathrm{Mo}_{3} \mathrm{Si}$ exceeds the highest peak of $\mathrm{Mo}_{5} \mathrm{SiB}_{2}$. This is in agreement with the ratio of phase contents in the desired $\mathrm{Mo}-12 \mathrm{Si}-8.5 \mathrm{~B}$ material, where $\mathrm{Mo} / \mathrm{Mo}_{3} \mathrm{Si} / \mathrm{Mo}_{5} \mathrm{SiB}_{2}$ mole and mass ratios are $8.23: 1.82: 1$ and $9.55: 1.86: 1$, respectively (here the densities of the three phases were assumed to be $10.22,8.97$, and $8.81 \mathrm{~g} / \mathrm{cm}^{3}$, respectively [7]). 


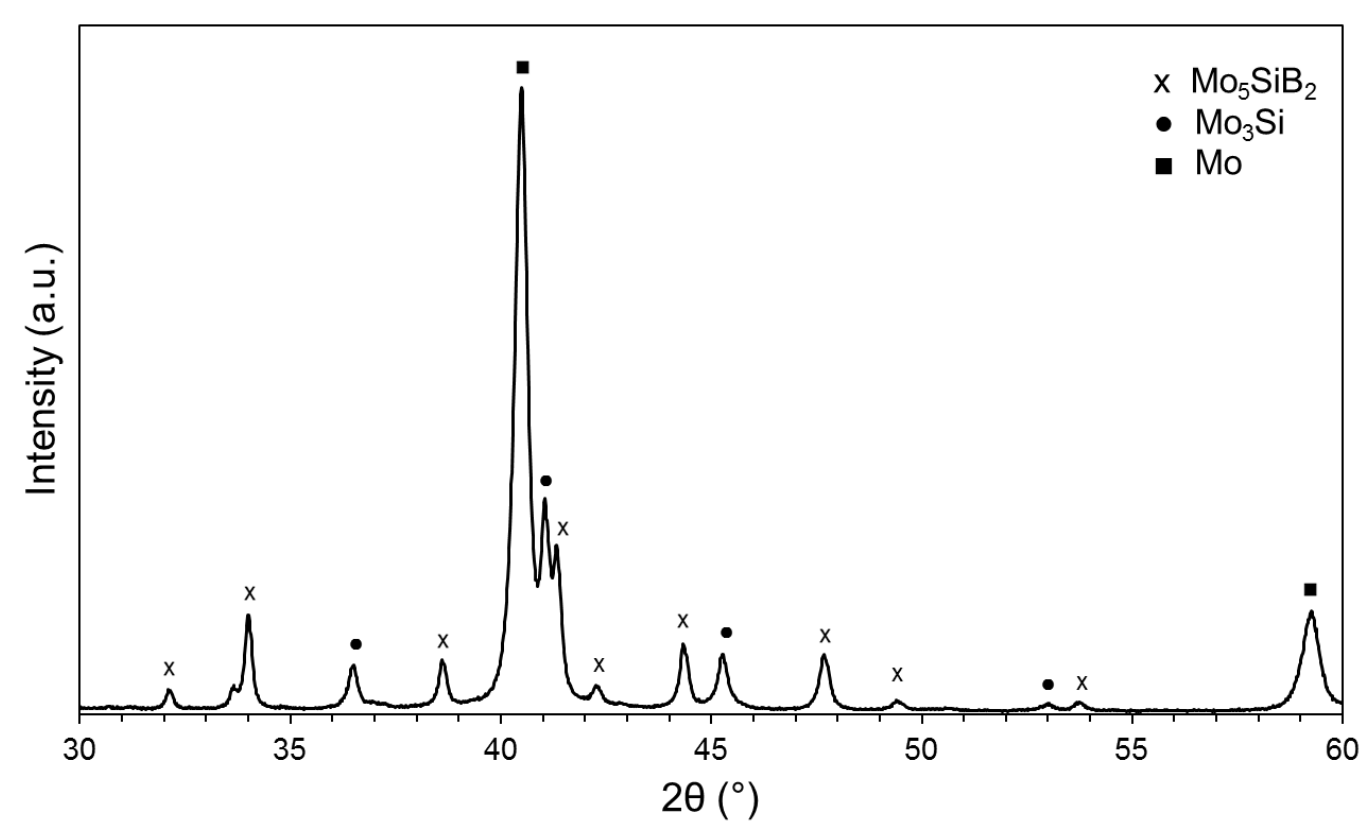

Fig. 9. XRD pattern of products obtained by combustion of Mo/12Si/8.5B mixture.

The compressive strength of $\mathrm{Mo}-12 \mathrm{Si}-8.5 \mathrm{~B}$ alloy synthesized by the chemical oven technique was as high as $524 \mathrm{MPa}$, while the density was in the range of $7.0-7.6 \mathrm{~g} / \mathrm{cm}^{3}$. Note that molybdenum possesses a compressive strength of $400 \mathrm{MPa}$ [38] and has a density of 10.2 $\mathrm{g} / \mathrm{cm}^{3}$, i.e. the obtained materials are stronger and lighter than molybdenum. To our knowledge, there are no data on compressive strength of $\mathrm{Mo}^{-}-12 \mathrm{Si}-8.5 \mathrm{~B}$ alloys prepared by arc melting in the literature, but it has been reported that these materials have a flexural strength of $539 \mathrm{MPa}$ at room temperature [7]. Apparently, Mo-12Si-8.5B materials obtained by chemical oven and arc melting have a similar strength.

\subsection{Oxidation of the obtained materials}

Figure 10 shows thermogravimetric curves obtained for the obtained materials heated in oxygen/argon $\left(20 \% \mathrm{O}_{2} / 80 \% \mathrm{Ar}\right)$ gas flow to a temperature of $1000{ }^{\circ} \mathrm{C}$, the maximum operating temperature of the used TGA instrument. Alumina crucibles were used, the gas flow rate was 30 $\mathrm{mL} / \mathrm{min}$, and the heating rate was $10{ }^{\circ} \mathrm{C} / \mathrm{min}$ in all runs. 


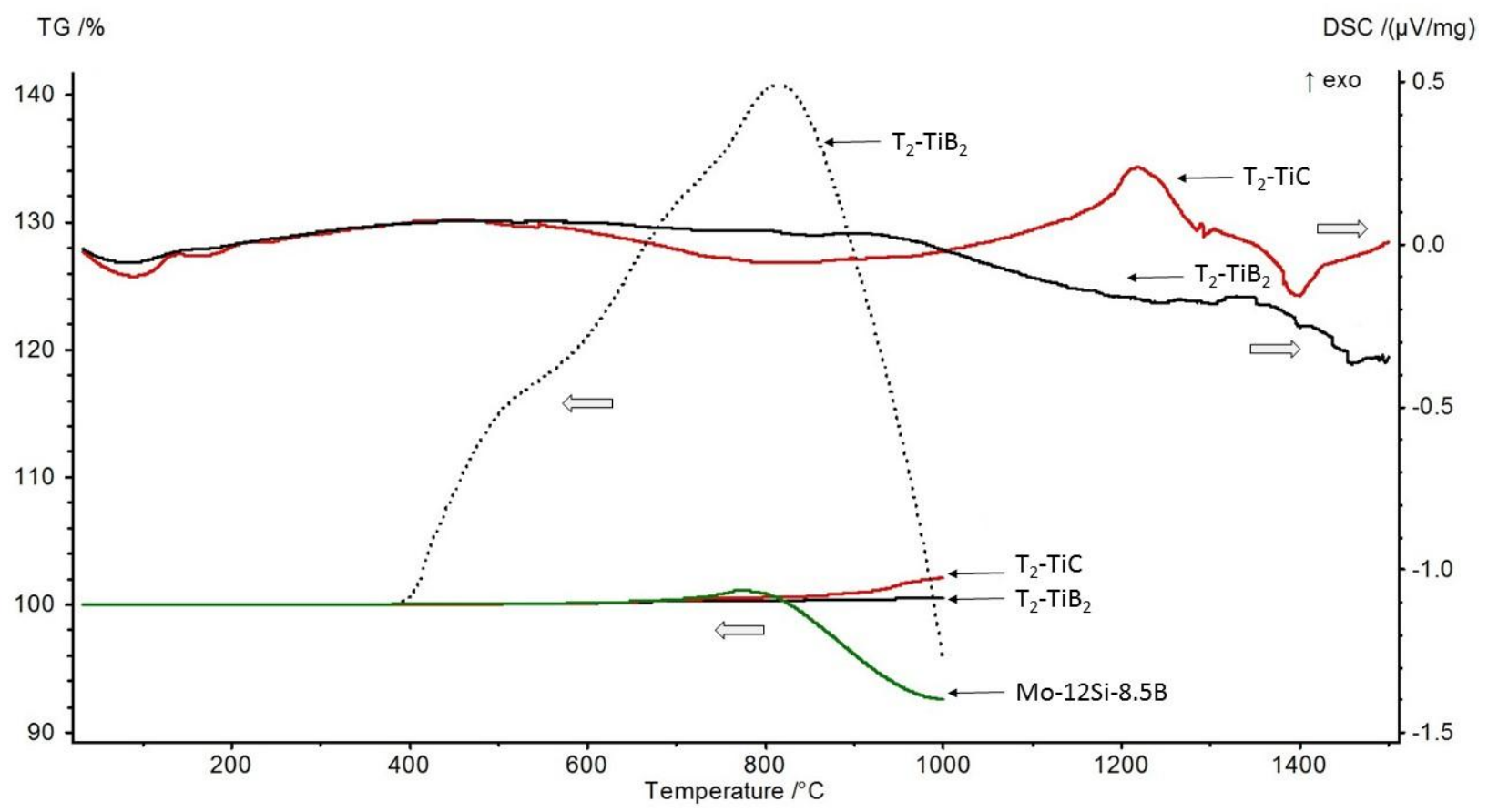

Fig. 10. TGA and DSC of the materials obtained by conventional SHS (dotted curve) and by the chemical oven technique (solid curves).

It is seen that oxidation of $\mathrm{Mo}_{5} \mathrm{SiB}_{2}-\mathrm{TiB}_{2}$ material obtained by conventional SHS starts at about $400{ }^{\circ} \mathrm{C}$. The sample exhibited a mass gain of about $40 \%$ at $800{ }^{\circ} \mathrm{C}$, followed by a catastrophic loss of mass.

$\mathrm{Mo}_{5} \mathrm{SiB}_{2}-\mathrm{TiB}_{2}$ materials obtained by the chemical oven technique are much more resistant to oxidation. The mass gain is about $0.3 \%$ at $700{ }^{\circ} \mathrm{C}$. The TG curve has a plateau at $700-800{ }^{\circ} \mathrm{C}$. With increasing the temperature to $1000{ }^{\circ} \mathrm{C}$, the mass gain increases to about $0.5 \%$. For $\mathrm{Mo}_{5} \mathrm{SiB}_{2}-\mathrm{TiC}$ material, the mass gain at $700{ }^{\circ} \mathrm{C}$ is about $0.4 \%$, but further heating leads to a mass gain of about $2 \%$ at $1000{ }^{\circ} \mathrm{C}$.

TG curves for $\mathrm{Mo}-12 \mathrm{Si}-8.5 \mathrm{~B}$ alloys show that they are more prone to oxidation than $\mathrm{Mo}_{5} \mathrm{SiB}_{2}-\mathrm{TiB}_{2}$ and $\mathrm{Mo}_{5} \mathrm{SiB}_{2}-\mathrm{TiC}$ materials (when all the materials were obtained by the chemical oven technique): the mass gain at $700-800{ }^{\circ} \mathrm{C}$ is larger and the loss of mass at $1000{ }^{\circ} \mathrm{C}$ is significant.

Since the TGA has shown that $\mathrm{Mo}_{5} \mathrm{SiB}_{2}-\mathrm{TiB}_{2}$ and $\mathrm{Mo}_{5} \mathrm{SiB}_{2}-\mathrm{TiC}$ materials obtained by the chemical oven technique exhibit the best oxidation resistance over the tested range of temperatures, their oxidation was also studied using the DSC instrument that allows tests to be performed over a wider range of temperatures, up to $1500{ }^{\circ} \mathrm{C}$. The DSC tests were conducted at the same gas flow rate and heating rate as in the TGA tests.

The DSC curve for $\mathrm{Mo}_{5} \mathrm{SiB}_{2}-\mathrm{TiC}$ material has a distinct exothermic peak with the maximum at about $1200{ }^{\circ} \mathrm{C}$. The onset of the peak is at about $800{ }^{\circ} \mathrm{C}$, which correlates with the TG curve for this material. There exists also an endothermic peak with the maximum at about $1400{ }^{\circ} \mathrm{C}$, which indicates endothermic phase transformation. In contrast, the DSC curve for $\mathrm{Mo}_{5} \mathrm{SiB}_{2}-\mathrm{TiB}_{2}$ material has a less distinct exothermic peak with the maximum at about $1320{ }^{\circ} \mathrm{C}$ and also a less distinct endothermic peak with the maximum at about $1450{ }^{\circ} \mathrm{C}$. 
Figures 11 and 12 show XRD patterns of $\mathrm{Mo}_{5} \mathrm{SiB}_{2}-\mathrm{TiC}$ and $\mathrm{Mo}_{5} \mathrm{SiB}_{2}-\mathrm{TiB}_{2}$ materials obtained by the chemical oven technique and heated to $1500{ }^{\circ} \mathrm{C}$ in $\mathrm{O}_{2} / \mathrm{Ar}$ flow. Comparison of these patterns with those in Figs. 5 and 6, respectively, shows that the oxidation led to the appearance of Mo phase and small peaks of $\mathrm{Mo}_{2} \mathrm{~B}$ in both materials. This may be associated with the formation of protective borosilicate coating. Indeed, if this coating forms, part of molybdenum is released from $\mathrm{T}_{2}$ phase, thus leading to the appearance of the aforementioned phases.

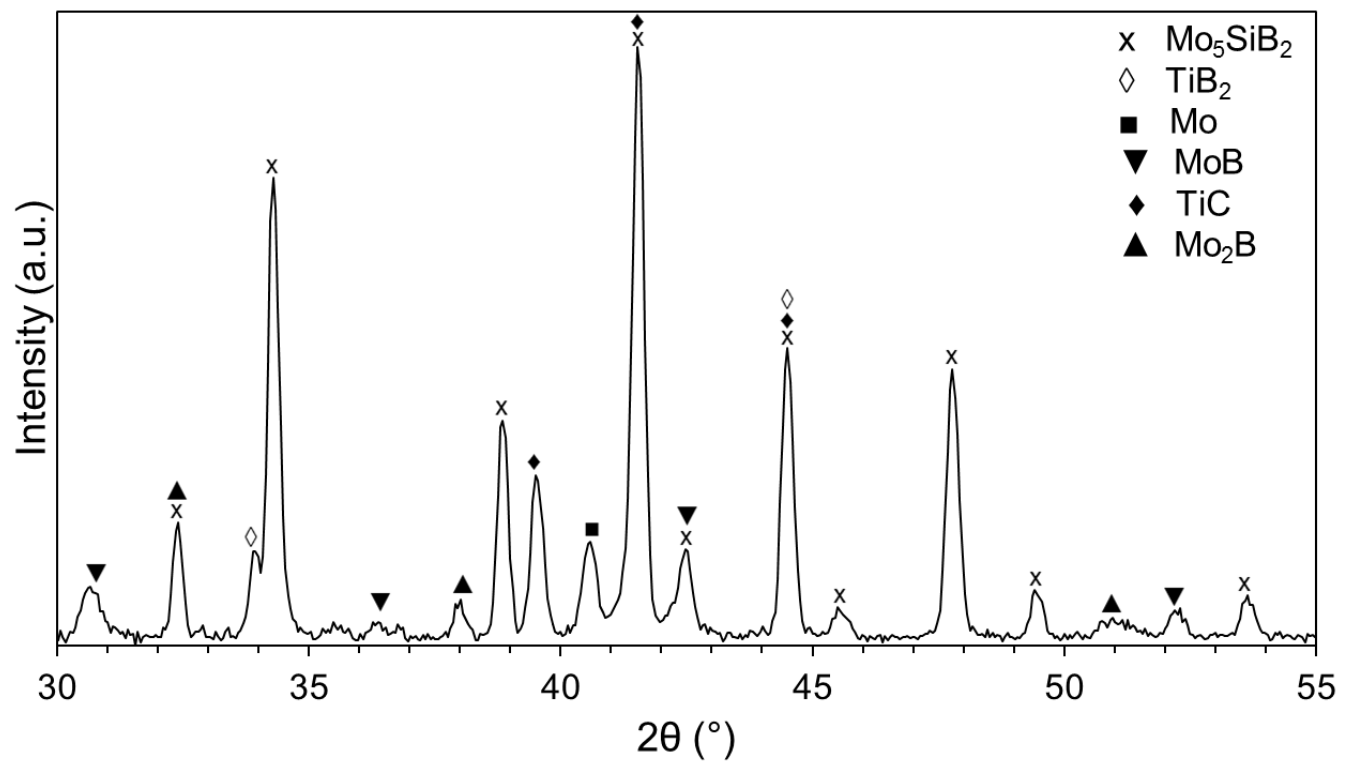

Fig. 11. XRD pattern of $\mathrm{Mo}_{5} \mathrm{SiB}_{2}-\mathrm{TiC}$ material obtained by the chemical oven technique and heated to $1500{ }^{\circ} \mathrm{C}$ in $\mathrm{O}_{2} / \mathrm{Ar}$ flow.

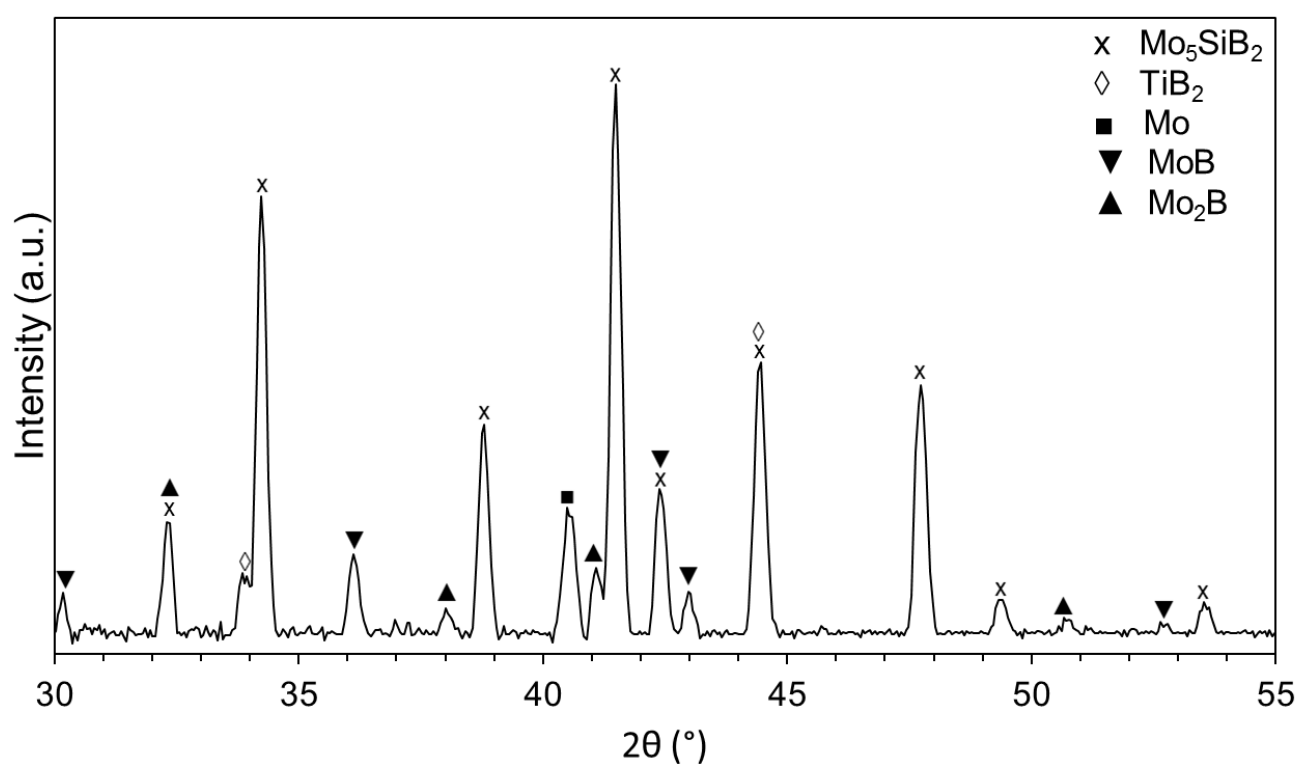

Fig. 12. XRD pattern of $\mathrm{Mo}_{5} \mathrm{SiB}_{2}-\mathrm{TiB}_{2}$ material obtained by the chemical oven technique and heated to $1500{ }^{\circ} \mathrm{C}$ in $\mathrm{O}_{2} /$ Ar flow. 
The formation of borosilicate coating also explains the exothermic and endothermic peaks on the DSC curves (Fig. 10). Indeed, the formation of borosilicate is an exothermic process because of its relatively high negative enthalpy of formation. The characteristic temperatures of the observed exothermic peaks are in agreement with the observations of a protective borosilicate layer in $\mathrm{Mo}-\mathrm{Si}-\mathrm{B}$ alloys in the temperature range of $1000-1300{ }^{\circ} \mathrm{C}$ [39]. The endothermic peaks are apparently associated with the volatilization of $\mathrm{B}_{2} \mathrm{O}_{3}$, which has been observed in 72-h isothermal oxidation tests of $\mathrm{Mo}-9 \mathrm{Si}-8 \mathrm{~B}$ alloy at $1300{ }^{\circ} \mathrm{C}$ [39].

The observation that $\mathrm{TiB}_{2}$-containing material has a better oxidation resistance than $\mathrm{TiC}$ containing product is worthy of further investigation. Since the contents of both $\mathrm{TiB}_{2}$ and $\mathrm{TiC}$ phases are relatively small, it is doubtful that their individual oxidation properties determine the oxidation behavior of the entire multi-phase material. It is more likely that the difference in the oxidation resistances is associated with the different concentrations of boron in $\mathrm{Mo}-\mathrm{Si}$ phases of the material because a small addition of boron dramatically improves the oxidation resistance of Mo-Si intermetallics [6].

In summary, the TGA and DSC results as well as XRD analysis of heated samples indicate that, among the materials fabricated in the present work, $\mathrm{Mo}_{5} \mathrm{SiB}_{2} / \mathrm{TiB}_{2}$ material obtained by the chemical oven technique is the most resistant to oxidation (at temperatures up to $1500{ }^{\circ} \mathrm{C}$ ). In the future, it would be desired to perform long-term isothermal oxidation tests of this material for a more reliable evaluation of its oxidation resistance.

\section{Conclusions}

Several materials based on $\mathrm{Mo}_{5} \mathrm{SiB}_{2}\left(\mathrm{~T}_{2}\right)$ phase have been obtained by mechanically activated combustion synthesis conducted in a conventional SHS mode and using the chemical oven technique.

Pellets of $\mathrm{Mo} / \mathrm{Si} / \mathrm{B} / \mathrm{Ti}$ mixtures, the composition of which corresponded to the formation of two-phase $\mathrm{Mo}_{5} \mathrm{SiB}_{2}-\mathrm{TiB}_{2}$ product $\left(10-40 \mathrm{wt} \% \mathrm{TiB}_{2}\right)$, exhibited a self-sustained propagation of a spinning combustion wave upon ignition at the top. The products were porous and contained secondary phases such as $\mathrm{Mo}_{5} \mathrm{Si}_{3}, \mathrm{MoB}$, and $\mathrm{Mo}$ in addition to the desired $\mathrm{Mo}_{5} \mathrm{SiB}_{2}$ and $\mathrm{TiB}_{2}$, which is explained by relatively low combustion temperatures. During TGA test in $\mathrm{O}_{2} / \mathrm{Ar}$ flow, the obtained materials exhibited a mass gain of about $40 \%$ at $800{ }^{\circ} \mathrm{C}$, followed by a catastrophic loss of mass.

The chemical oven technique, involving combustion of a highly exothermic Ti/B mixture shell, has enabled fabrication of denser $\mathrm{Mo}_{5} \mathrm{SiB}_{2}$-based materials with $\mathrm{TiC}$ and $\mathrm{TiB}_{2}$ additives as well as synthesis of $\alpha-\mathrm{Mo}_{-}-\mathrm{Mo}_{5} \mathrm{SiB}_{2}-\mathrm{Mo}_{3} \mathrm{Si}(\mathrm{Mo}-12 \mathrm{Si}-8.5 \mathrm{~B})$ alloy. The products had low contents of secondary phases as compared with $\mathrm{Mo}_{5} \mathrm{SiB}_{2}-\mathrm{TiB}_{2}$ materials obtained by conventional SHS. The Mo-12Si-8.5B material was stronger and lighter than molybdenum. During TGA test in $\mathrm{O}_{2} / \mathrm{Ar}$ flow, however, it lost several percent of mass at $1000{ }^{\circ} \mathrm{C}$. The oxidation resistance of $\mathrm{Mo}_{5} \mathrm{SiB}_{2}-\mathrm{TiC}$ and $\mathrm{Mo}_{5} \mathrm{SiB}_{2}-\mathrm{TiB}_{2}$ materials obtained by the chemical oven technique was much better. The latter was especially resistant to the oxidation at temperatures up to $1500{ }^{\circ} \mathrm{C}$ (the maximum temperature in the test) and also had higher elastic modulus and hardness than the former.

\section{Acknowledgments}

This material is based upon work supported by the Department of Energy under Award Number DE-FE0008470. This work was also supported by Climax Molybdenum, Inc. The authors thank Yirong Lin and Ricardo Martinez for assistance with nanoindentation tests. 


\section{Disclaimer}

This report was prepared as an account of work sponsored by an agency of the United States Government. Neither the United States Government nor any agency thereof, nor any of their employees, makes any warranty, express or implied, or assumes any legal liability or responsibility for the accuracy, completeness, or usefulness of any information, apparatus, product, or process disclosed, or represents that its use would not infringe privately owned rights. Reference herein to any specific commercial product, process, or service by trade name, trademark, manufacturer, or otherwise does not necessarily constitute or imply its endorsement, recommendation, or favoring by the United States Government or any agency thereof. The views and opinions of authors expressed herein do not necessarily state or reflect those of the United States Government or any agency thereof.

\section{References}

1. J.H. Perepezko, The hotter the engine, the better, Sci. 326 (2009) 1068-1069.

2. D.M. Dimiduk, J.H. Perepezko, Mo-Si-B Alloys: Developing a revolutionary turbine-engine material, MRS Bull. 28 (2003) 639-645.

3. J.H. Perepezko, R. Sakidja, K.S. Kumar, in: W. Soboyejo (Ed.), Mo-Si-B Alloys for ultrahigh temperature applications, Advanced Structural Material CRC Press, Boca Raton, (2007).

4. J.A. Lember, R.O. Ritchie, Mo-Si-B alloys for ultrahigh-temperature structural applications, Adv. Mater. 24 (2012) 3445-3480.

5. R. Mitra, Mechanical behavior and oxidation resistance of structural silicides, Int. Mater. Rev. 51 (2006) 13-60.

6. M. Akinc, M.K. Meyer, M.J. Kramer, A.J. Thom, J.J. Huebsch, B. Cook, Boron-doped molybdenum silicides for structural applications, Intermet. A 261 (1999) 16-23.

7. J.H. Schneibel, M.J. Kramer, O. Unal, R.N. Wright, Processing and mechanical properties of a molybdenum silicide with the composition Mo-12Si-8.5B (at.\%), Intermet. 9 (2001) 25-31.

8. H. Choe, D. Chen, J.H. Schneibel, R.O. Ritchie, Ambient to high temperature fracture toughness and fatigue-crack propagation behavior in a Mo-12Si-8.5B (at.\%) intermetallic, Intermet. 9 (2001) 319-329.

9. M. Kruger, S. Franz, H. Saage, M. Heilmaier, J.H. Schneibel, P. Jehanno, M. Boning, H. Kestler, Mechanically alloyed Mo-Si-B alloys with a continuous $\alpha$-Mo matrix and improved mechanical properties, Intermet. 16 (2008) 933-941.

10. J. Shackelford, W. Alexander. CRC Materials Science and Engineering Handbook, 3rd ed., CRC Press, Boca Raton. (2000)

11. S. Miyamoto, K. Yoshimi, S.-H. Ha, T. Kaneko, J. Nakamura, T. Sato, K. Maruyama, R. Tu, T. Goto, Metall. Phase equilibria, microstructure, and high-temperature strength of TiCadded Mo-Si-B alloys, Mater. Trans. A 45A (2014) 1112-1123.

12. K. Yoshimi, J. Nakamura, D. Kanekon, S. Yamamoto, K. Maruyama, H. Katsui, T. Goto, High-temperature compressive properties of TiC-added Mo-Si-B alloys, JOM 66 (2014) 1930-1938.

13. R. Munro, Elastic-stiffness coefficients of titanium diboride, J. Res. Natl. Inst. Stand. Technol. 105 (2000) 709-720

14. A. Yamauchi, K. Yoshimi, K. Kurokawa, S. Hanada, Synthesis of Mo-Si-B in situ composites by mechanical alloying, J. Alloy. Compd. 434-435 (2007) 420-423. 
15. P. Jehanno, M. Heilmaier, H. Saage, M. Boning, H. Kestler, J. Freudenberger, S. Drawin, Assessment of the high temperature deformation behavior of molybdenum silicide alloys, Mater. Sci Eng. A 463 (2007) 216-223.

16. C. Gras, E. Gaffet, F. Bernard, Combustion wave structure during the $\mathrm{MoSi}_{2}$ synthesis by mechanically-activated self-propagating high-temperature synthesis (MASHS): In situ timeresolved investigations, Intermet. 14 (2006) 521-529.

17. M.A. Korchagin, D.V. Dudina, Application of self-propagating high-temperature synthesis and mechanical activation for obtaining nanocomposites, Combust. Explos. Shock Waves 43 (2007) 176-187.

18. M.S. Alam, E. Shafirovich, Mechanically activated combustion synthesis of molybdenum silicides and borosilicides for ultrahigh-temperature structural applications, Proc. Combust. Inst. 35 (2015) 2275-2281.

19. A.G. Merzhanov, A.K. Filonenko, I.P. Borovinskaya, New phenomena in combustion of condensed systems, Sov. Phys. Dokl. 208 (1973) 122-125.

20. A. Bayliss, B.J. Matkowsky, A.P. Aldushin, Dynamics of hot spots in solid fuel combustion, Phys. D 166 (2002) 104-130.

21. T.P. Ivleva, A.G. Merzhanov, Three-dimensional modes of unsteady solid-flame combustion, Chaos 13 (2003) 80-86.

22. F. Álvarez, C. White, A.K. Narayana Swamy, E. Shafirovich, Combustion wave propagation in mixtures of JSC-1A lunar regolith simulant with magnesium, Proc. Combust. Inst. 34 (2013) 2245-2252.

23. M.W. Chase, NIST-JANAF thermochemical tables, J. Phys. Chem. Ref. Data, Monograph 9 (1998) 1-1951.

24. A.A. Shiryaev, Thermodynamics of SHS processes: Advanced approach, Int. J. SHS 4 (1995) $351-362$

25. E.A. Levashov, Yu.S. Pogozhev, A.Yu. Potanin, N.A.Kochetov, D.Yu. Kovalev, N.V. Shvyndina, T.A. Sviridova, Self-propagating high-temperature synthesis of advanced ceramics in the Mo-Si-B system: Kinetics and mechanism of combustion and structure formation, Ceram. Int. 40 (2014) 6541-6552.

26. A. Delgado, E. Shafirovich, Towards better combustion of lunar regolith with magnesium, Combust. Flame 160 (2013) 1876-1882.

27. R.R. Asamoto, P.E. Novak, Tungsten-rhenium thermocouples for use at high temperatures, Rev. Sci. Instr. 39 (1968) 1233.

28. K. Itoa, K. Ihara, K. Tanaka, M. Fujikura, M. Yamaguchi, Physical and mechanical properties of single crystals of the $\mathrm{T}_{2}$ phase in the Mo-Si-B system, Intermet. 9 (2001) 591602.

29. K. Ihara, K. Ito, K. Tanaka, M. Yamaguchi, Mechanical properties of $\mathrm{Mo}_{5} \mathrm{SiB}_{2}$ single crystals, Mater. Sci. Eng. A329-331 (2002) 222-227.

30. P.G. Biragoni, M. Heilmaier, FEM-Simulation of real and artificial microstructures of MoSi-B alloys for elastic properties and comparison with analytical methods, Adv. Eng. Mater. 9 (2007) 882-887.

31. V.I. Yukhvid, Modifications of SHS processes, Pure Appl. Chem. 64 (1992) 977-988.

32. R.V. Raman, S.V. Rele, S. Poland, J. LaSalvia, M.A. Meyers, A.R. Niiler, The one-step synthesis of dense titanium carbide tiles, JOM 47 (1995) 23-25.

33. E. Y. Gutmanas, I. Gotman, Dense high-temperature ceramics by thermal explosion under pressure, J. Europ. Ceram. Soc. 19 (1999) 2381-2393. 
34. E.A. Olevsky, E.R. Strutt, M.A. Meyers, Combustion synthesis and quasi-isostatic densification of powder cermets, J. Mater. Process. Technol. 121 (2002) 157-166.

35. Q. Xu, X. Zhang, J. Han, X. He, V.L. Kvanin, Combustion synthesis and densification of titanium diboride-copper matrix composite, Mater. Lett. 57 (2003) 4439-4444.

36. D. Vallauri, V.A. Shcherbakov, A.V. Khitev, F.A. Deorsola, Study of structure formation in $\mathrm{TiC}-\mathrm{TiB}_{2}-\mathrm{Me}_{\mathrm{x}} \mathrm{O}_{\mathrm{y}}$ ceramics fabricated by SHS and densification, Acta Mater. 56 (2008) 1380-1389.

37. M. Martinez Pacheco, R.H.B. Bouma, L. Katgerman, Combustion synthesis of TiB 2 -based cermets: modeling and experimental results, Appl. Phys. A 90 (2008) 159-163.

38. ASM Handbook, Vol.2: Properties and Selection: Nonferrous Alloys and Special-Purpose Materials, $10^{\text {th }}$ ed., ASM International, Materials Park, OH, 1990.

39. B. Gorr, L. Wang, S. Burk, M. Azim, S. Majumdar, H.-J. Christ, D. Mukherji, J. Rösler, D. Schliephake, M. Heilmaier, High-temperature oxidation behavior of Mo-Si-B-based and CoRe-Cr-based alloys, Intermet. 48 (2014) 34-43. 


\section{Graphical Abstract}

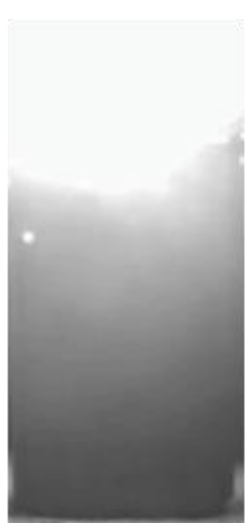

0

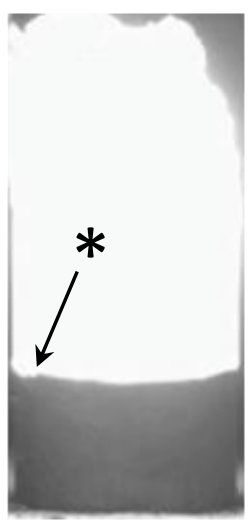

0

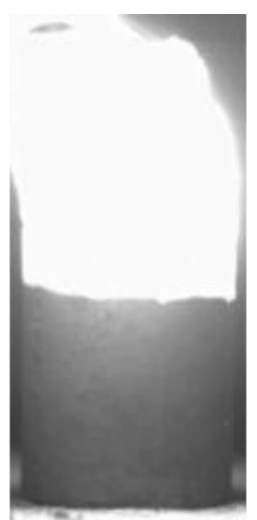

$0.7 \mathrm{~s}$

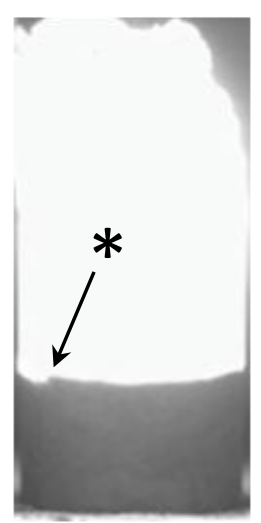

$0.02 \mathrm{~s}$

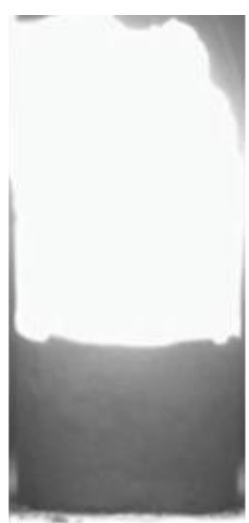

1.4

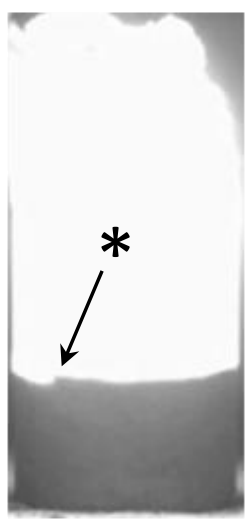

$0.04 \mathrm{~s}$

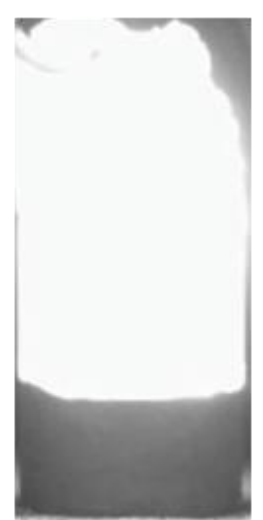

$2.1 \mathrm{~s}$

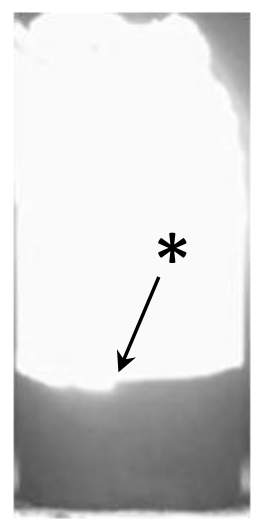

$0.06 \mathrm{~s}$

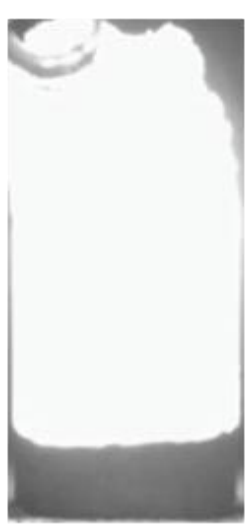

$2.8 \mathrm{~s}$

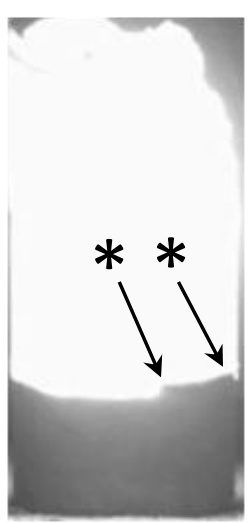

$0.08 \mathrm{~s}$

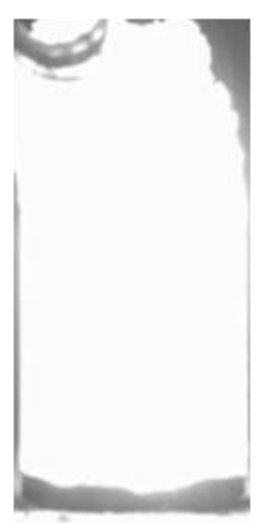

$3.5 \mathrm{~s}$

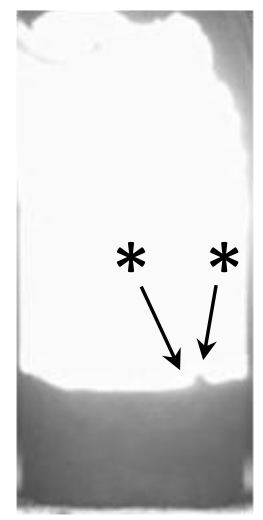

$0.1 \mathrm{~s}$ 